\title{
Stabilization of Clayey Soils Using Chloride Components
}

\author{
Habiba Afrin \\ Civil Engineering Department, Rajshahi University of Engineering and Technology, Rajshahi, Bangladesh
}

\section{Email address:}

afrinmeno@gmail.com

\section{To cite this article:}

Habiba Afrin. Stabilization of Clayey Soils Using Chloride Components. American Journal of Civil Engineering. Vol. 5, No. 6, 2017, pp. 365-370. doi: 10.11648/j.ajce.20170506.18

Received: June 2, 2017; Accepted: July 5, 2017; Published: November 29, 2017

\begin{abstract}
Soils exhibit generally undesirable engineering properties. Soil Stabilization is the alteration of soils to enhance their physical properties. Stabilization can increase the shear strength of a soil and/or control the shrink-swell properties of a soil, thus improving the load bearing capacity of a sub-grade to support pavements and foundations. Stabilization and its effect on soil indicate the reaction mechanism with additives, effect on its strength, improve and maintain soil moisture content and suggestion for construction systems. The main objective of this paper is to improve the physical and chemical properties of clay soil by using chemical additives like chloride compounds as $\mathrm{NaCl}, \mathrm{CaCl}_{2}$ and $\mathrm{MgCl}_{2}$. Various proportions of $\mathrm{NaCl}, \mathrm{CaCl}_{2}$ and $\mathrm{MgCl}_{2}$ was mixed with soil and basic engineering properties such as specific gravity, liquid limit, compaction characteristics and consolidation parameters were determined. It has been observed that an addition of different percentages like $4 \%, 8 \%$ and $12 \%$ of chloride compounds into clayey soils increased the dry density and decreased the moisture content. The liquid limit, plastic limit and plasticity index decreased with the increase in chemical content. This appears due to the fact that addition of $\mathrm{NaCl}, \mathrm{CaCl}_{2}$ and $\mathrm{MgCl}_{2}$ filled up the voids between particles of soil as particle size of $\mathrm{NaCl}, \mathrm{CaCl}_{2}$ and $\mathrm{MgCl}_{2}$ is smaller than soil particles and can be easily replaced the voids. The compression index and swelling index was decreased with the increase in chloride compound percentage.
\end{abstract}

Keywords: Soil Stabilization, Clay Soil, Grain Size Distribution, Atterberg Limits, Standard Proctor Test, Consolidation

\section{Introduction}

Soil stabilization may be defined as the alteration or preservation of one or more soil properties to improve the engineering characteristics and performance of a soil. Stabilization, in a broad sense, incorporates the various methods employed for modifying the properties of a soil to improve its engineering performance. Soil stabilization refers to the procedure in which a special soil, cementing material, or other chemical materials are added to a natural soil to improve one or more of its properties. One may achieve stabilization by mechanically mixing the natural soil and stabilizing material together so as to achieve a homogeneous mixture or by adding stabilizing material to an undisturbed soil deposit and obtaining interaction by letting it permeate through soil voids [1]. Soil stabilizing additives are used to improve the properties of less-desirable rood soils. When used these stabilizing agents can improve and maintain soil moisture content, increase soil particle cohesion and serve as cementing and water proofing agents [2]. A difficult problem in civil engineering works exists when the sub-grade is found to be clay soil. Soils having high clay content have the tendency to swell when their moisture content is allowed to increase [3]. When the mechanical stability of a soil cannot be obtained by combining materials, it may be advisable to stabilize the soil by adding lime, cement, bituminous materials or special additives. Many research have been done on the subject of soil stabilization using various additives, the most common methods of soil stabilization of clay soils in pavement work are cement and lime stabilization. The high strengths obtained from cement and lime stabilization may not always be required, however, and there is justification for seeking cheaper additives which may be used to alter the soil properties. Lime or calcium carbonate is oldest traditional chemical stabilizer used for soil stabilization. However soil stabilization using lime, sodium carbonate, sodium chloride, calcium chloride and magnesium chloride involve advantages and disadvantages. The study provides details of advantages and disadvantages of using chemicals above as soil stabilizer. 


\section{Material Used}

\subsection{Soil}

Clays tend to have low shear strengths and to lose shear strength further upon wetting or other physical disturbances. They can be plastic and compressible and they expand when wetted and shrink when dried. Some types expand and shrink greatly upon wetting and drying - a very undesirable feature. Soil used in this study is a Browne gray clayey silt of intermediate plasticity [4]. This soil is normally defined as Clay soil. The soil is collected from shallow depth from Ghodaghari Rajabari rural field in Rajshahi of Bangladesh.

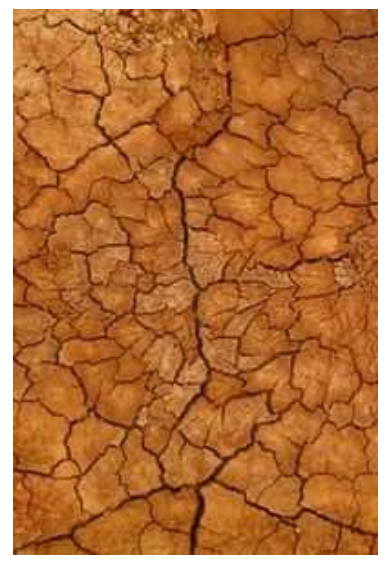

Figure 1. Clay Soil expands and contracts.

The soil samples were taken at a depth of about $(1 \mathrm{~m})$ below the ground surface. The properties of the soil, and atterberg limits are given in table (1) while the classification and the grain size distribution of the soil are shown in Fig. (2) and Fig. (3). Thus the soil is classified as clay soil $(\mathrm{CH})$ according to the unified classification system.

By performing grain size distribution of collected soil sample, figure-2 shows the percent finer vs. particle size (mm) curve.

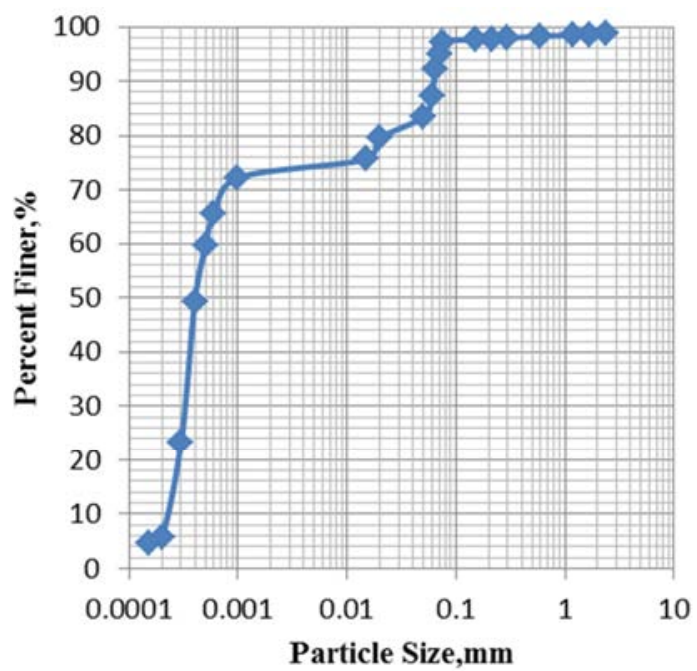

Figure 2. Grain size distribution curve of collected soil Sample.

Table 1. Geotechnical Properties of used soil in this research.

\begin{tabular}{ll}
\hline INDEX PROPERTY & CONSTITUENTS \\
\hline Specific Gravity & 2.67 \\
Liquid Limit, LL\% & $43 \%$ \\
Plastic Limit, PL\% & $24.66 \%$ \\
Plasticity Index, PI\% & $18.34 \%$ \\
Optimum Moisture Content, OMC\% & $14.42 \%$ \\
Maximum Dry Density, $\gamma_{\mathrm{dmax}}$ & $1.87 \mathrm{gm} / \mathrm{cm}^{3}$ \\
Grain Size Distribution & \\
Textural soil classification Type of soil & Clay \\
Uniformity Co-efficient & 2.63 \\
$\mathrm{D}_{10}$ & $0.0019 \mathrm{~mm}$ \\
$\mathrm{D}_{50}$ & $0.0035 \mathrm{~mm}$ \\
$\mathrm{D}_{60}$ & $0.005 \mathrm{~mm}$ \\
\hline
\end{tabular}

From above figure the soil contains sand $6.55 \%$, silt $32.25 \%$ and clay $61.20 \%$.

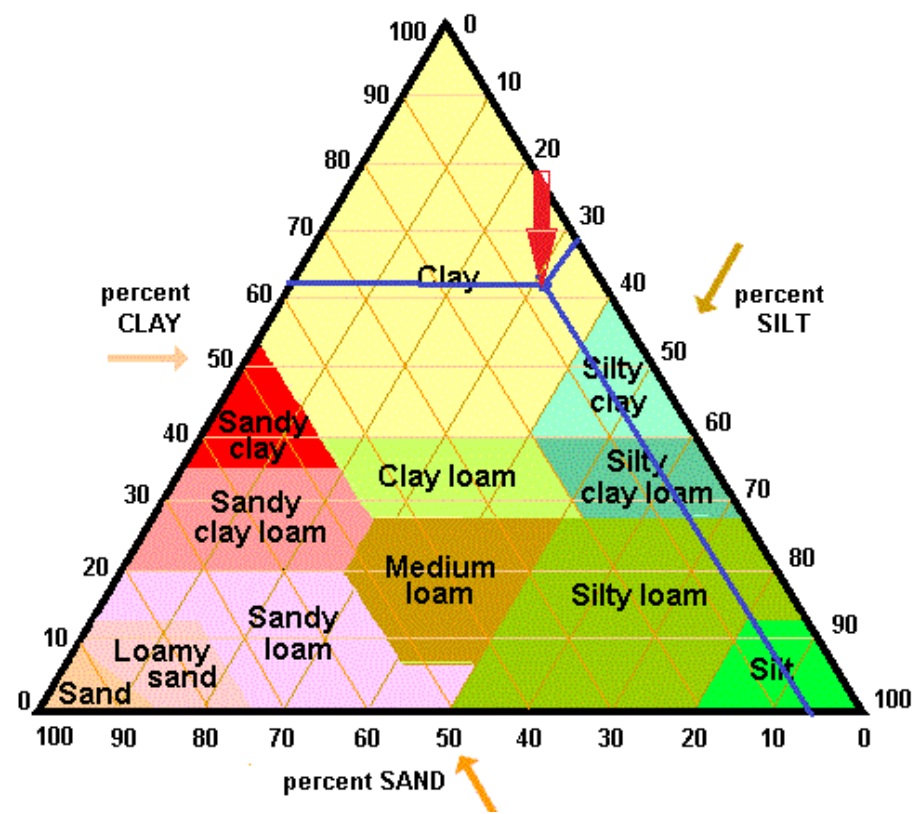

Figure 3. Textural soil distribution chart. 


\subsection{Soaking Solutions}

Distilled water was used in all tests. Common salt falls under water-retaining agents used in soil stabilization to improve soil strength, bearing capacity and durability under adverse moisture and stress conditions. They gave the following interrelated effects of the stabilizing effect of sodium chloride on clay - sand gravel aggregates; coagulation of clay particles, reduction in tendency of clay to expand when wet, reduction in volume shrinkage in clay, retardation of permeability of soil water, lowering of moisture film thickness in soil, thus retarding out [5]. The concentration of each chloride salt $\left(\mathrm{NaCl}, \mathrm{MgCl}_{2}\right.$, and $\mathrm{CaCl}_{2}$ ) was obtained by dissolving in distilled water to obtain the specific concentration for each type of salt in ppm, and then mixed with soil. The soil specimens were prepared by modified Procter test procedures according to ASTM (American Society for testing and materials) (D 1557). Three different concentrations for each chloride salt $(4 \%, 8 \%$ and $12 \%)$ were prepared.

\section{Soil Tests}

\subsection{Standard Proctor Test}

The standard proctor test is used to determine the moisture content \& dry density relationship according to ASTM 698(2002) of a soil for a specified compactive effort. Each chloride compounds $\left(\mathrm{NaCl}, \mathrm{MgCl}_{2}, \mathrm{CaCl}_{2}\right)$ were dissolved in water and mixed with soil then left for one day. The mold is filled with three equal layers of soil and each layer is compacted with $5.5 \mathrm{lb}$ hammer falling a distance $1 \mathrm{ft}$ by 25 drops of the hammer. Performing the test with various percentages of chloride ( $4 \%, 8 \%$ and $12 \%)$ is mixed with soil to enhance its effectiveness of clay soil. Figure- 4 shows the dry density-moisture content relation for different salts and different percentages.

\subsection{Atterberg Limits}

The Atterberg limits are a basic measure of the critical water contents of a fine-grained soil, such as its shrinkage limit, plastic limit, and liquid limit. The liquid limit test has been conducted using the Cassagrande apparatus according to ASTM (D423-66). The plastic limit test was conducted according to the ASTM (D 424-59). These tests were carried out to investigate the effect of addition of salt on the consistency limits. Figure-5 shows the effect of salt content on the Atterberg limits.

\subsection{Consolidation Test}

The test is carried out by applying a sequin about one quarter of its diameter. ASTM D 2435 - Standard Test Method for One-Dimensional Consolidation (2002) Properties of Soils is followed [6].
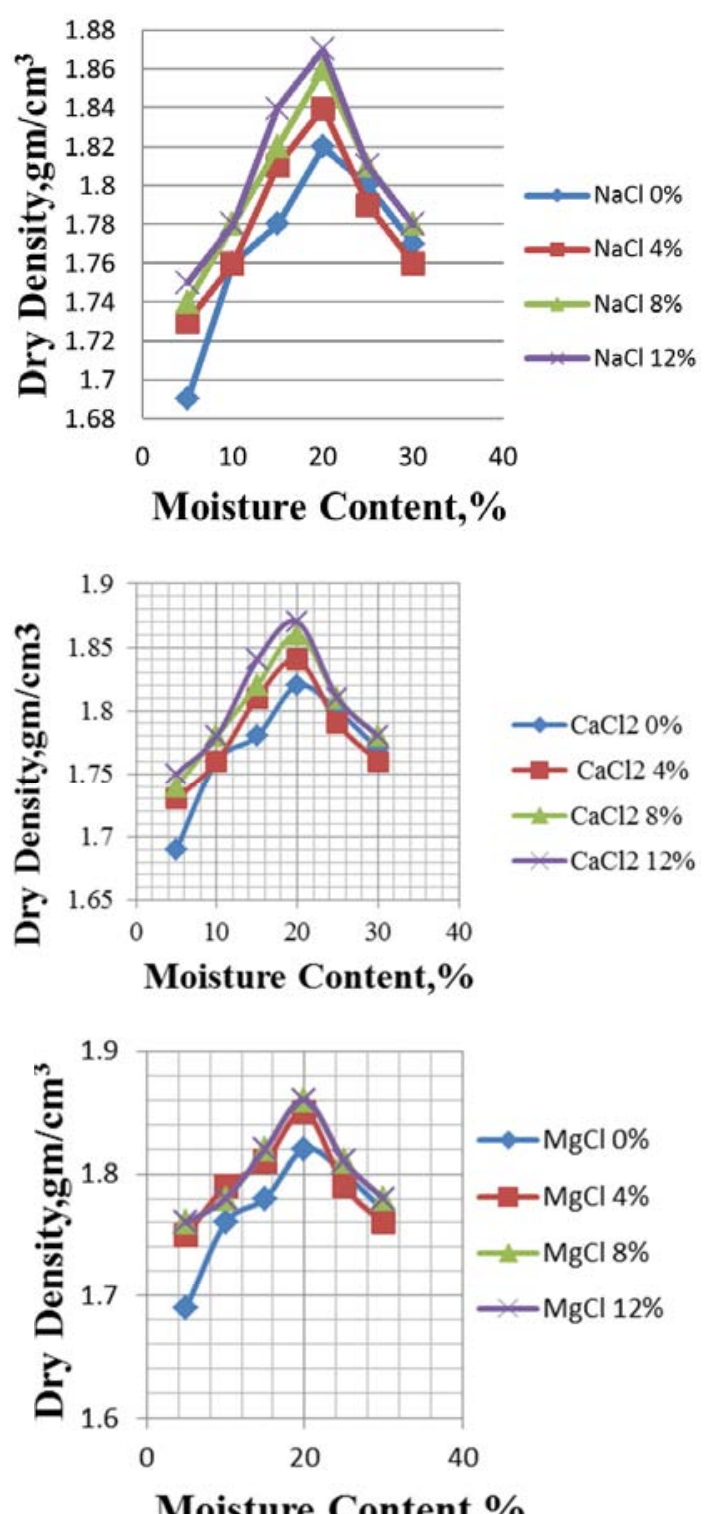

Moisture Content, $\%$

Figure 4. Shows the dry density vs moisture content relation for different percentages of chloride.

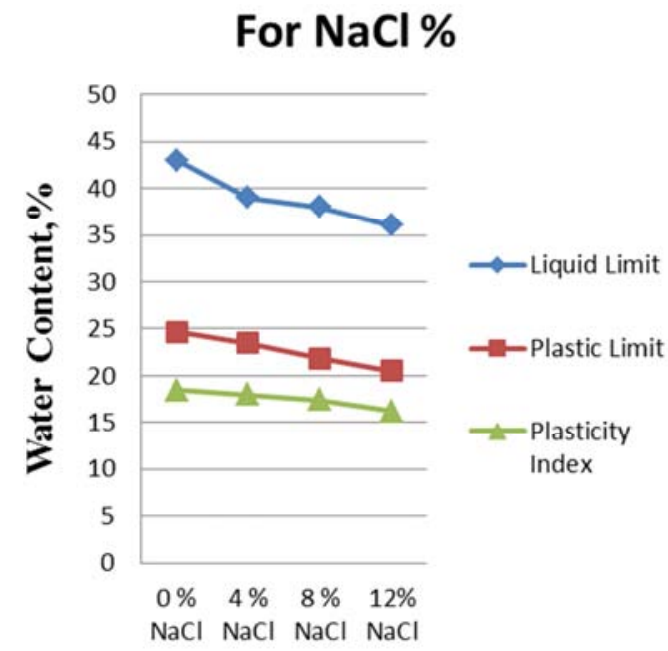




\section{For $\mathrm{CaCl}_{2} \%$}

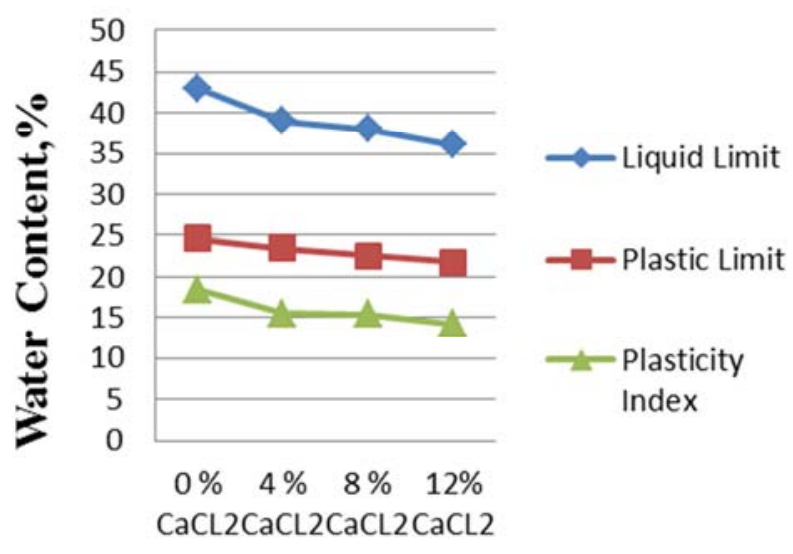

For $\mathrm{MgCl}_{2} \%$

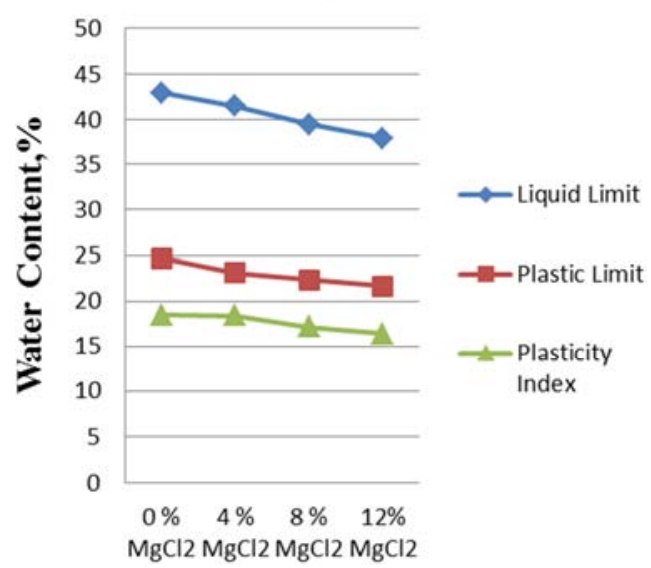

Figure 5. Effect of various salt percentage and moisture content on engi neering properties of soil.

Table 2. For compression index of soil for different percentage of salts.

\begin{tabular}{llll}
\hline \% of $\mathbf{~ N a C l} / \mathbf{C a C l}_{2} / \mathbf{M g C l}_{\mathbf{2}}$ & Compression Index, $\mathbf{C}_{\mathbf{c}}(\mathbf{F o r ~} \mathbf{N a C l})$ & Compression Index, $\mathbf{C}_{\mathbf{c}}\left(\mathbf{F o r ~}_{\mathbf{C a C l}}\right)$ & $\mathbf{C o m p r e s s i o n ~ I n d e x}, \mathbf{C}_{\mathbf{c}}(\mathbf{F o r} \mathbf{M g C l})$ \\
\hline 0 & 0.28 & 0.28 & 0.28 \\
4 & 0.24 & 0.23 & 0.25 \\
8 & 0.18 & 0.20 & 0.21 \\
12 & 0.14 & 0.17 & 0.19 \\
\hline
\end{tabular}

Table 3. For swelling index of soil for different percentage of salts.

\begin{tabular}{llll}
\hline \% of $\mathbf{~ N a C l} / \mathbf{C a C l}_{2} / \mathbf{M g C l}_{\mathbf{2}}$ & Swelling Index, $\mathbf{C}_{\mathbf{s}}(\mathbf{F o r ~} \mathbf{~ N a C l})$ & Swelling Index, $\mathbf{C}_{\mathbf{s}}\left(\mathbf{F o r ~}_{\mathbf{C a C l}}\right)$ & $\mathbf{S w e l l i n g}_{\mathbf{I n d e x}}, \mathbf{C}_{\mathbf{s}}(\mathbf{F o r} \mathbf{M g C l})$ \\
\hline 0 & 0.033 & 0.033 & 0.033 \\
4 & 0.028 & 0.027 & 0.025 \\
8 & 0.024 & 0.023 & 0.022 \\
12 & 0.018 & 0.019 & 0.017 \\
\hline
\end{tabular}

In figure-6: is shown compression index vs. percentage of salts curve.

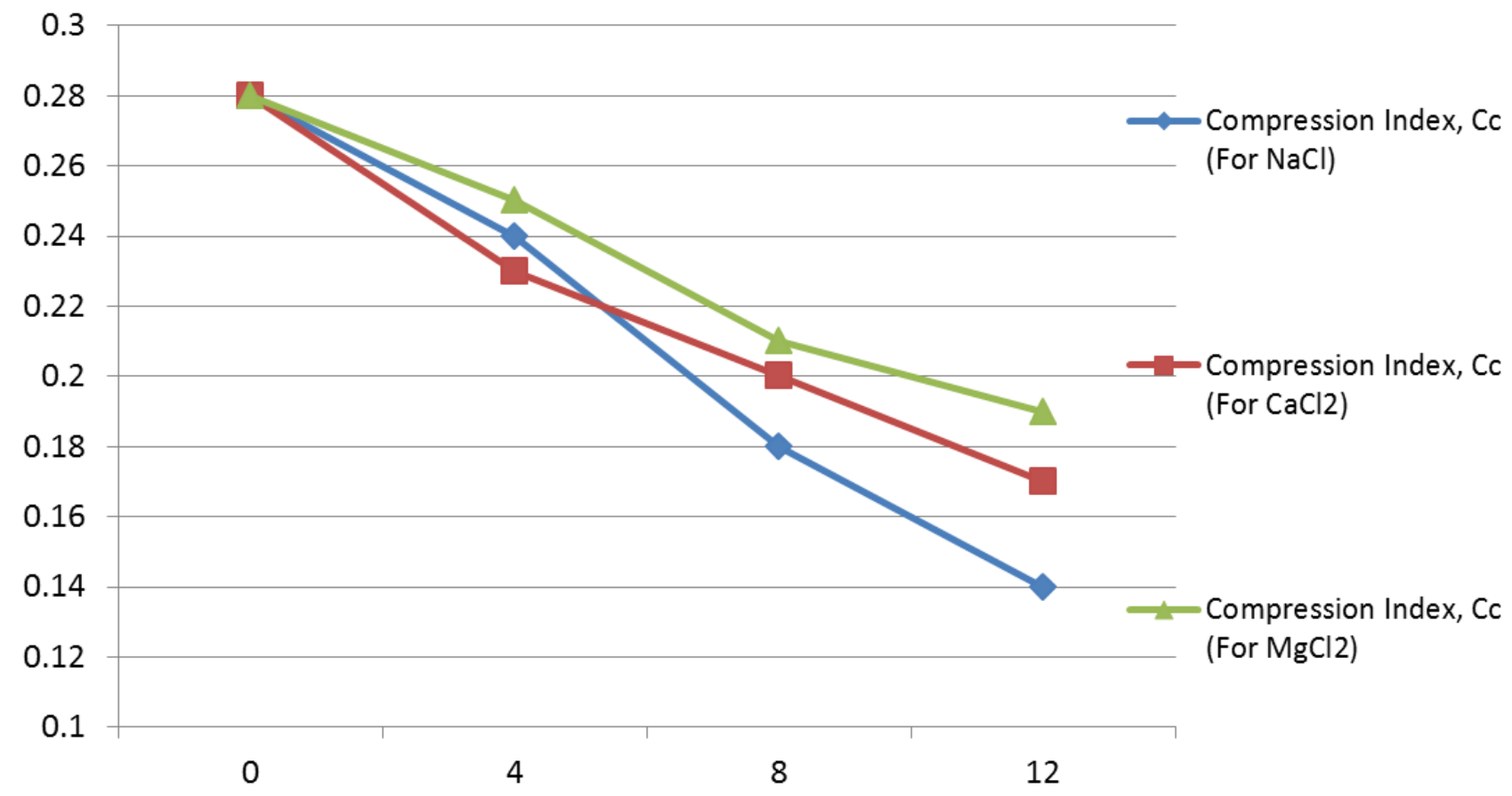

Figure 6. Swelling Index vs. percentage of salts curve.

In figure-7 is shown compression index vs. percentage of salts curve. 


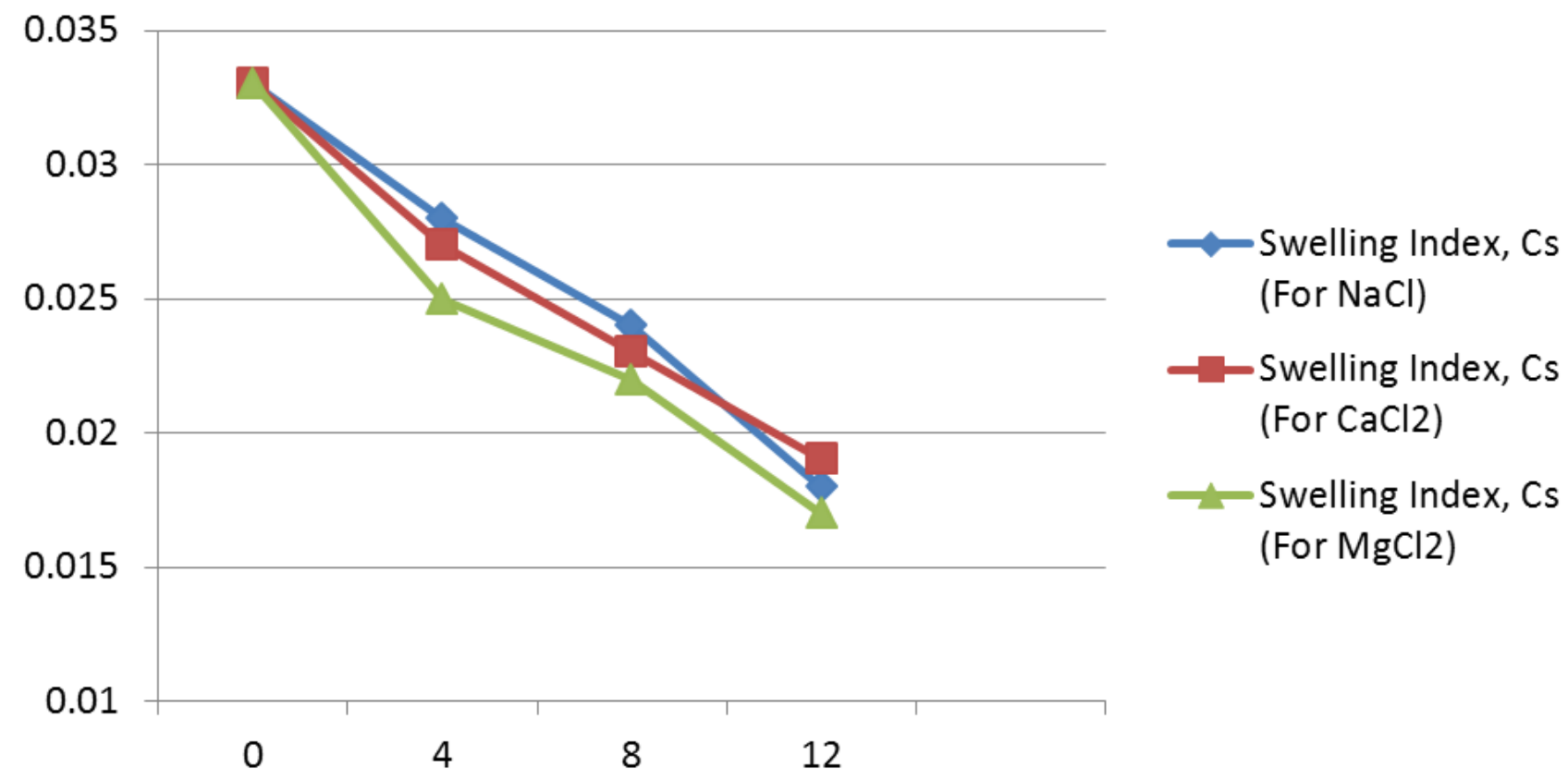

Figure 7. Swelling Index vs. percentage of salts curve.

\section{Results and Discussion}

\subsection{Compaction Test}

It is found that the dry density of soil is increases with the increased proportion of $\mathrm{NaCl}, \mathrm{CaCl}_{2}$ and $\mathrm{MgCl}_{2}$. As the dry density of soil without any mixture are $1.82 \mathrm{gm} / \mathrm{cm}^{3}$. With the increased percentage of $4 \%, 8 \%$ and $12 \%$ of $\mathrm{NaCl}$ dry density respectively $1.83 \mathrm{gm} / \mathrm{cm}^{3}, 1.84 \mathrm{gm} / \mathrm{cm}^{3}$ and 1.84 $\mathrm{gm} / \mathrm{cm}^{3}$. With the increased percentage of $4 \%, 8 \%$ and $12 \%$ of $\mathrm{CaCl}_{2}$ dry density respectively $1.84 \mathrm{gm} / \mathrm{cm}^{3}, 1.86 \mathrm{gm} / \mathrm{cm}^{3}$ and $1.87 \mathrm{gm} / \mathrm{cm}^{3}$. With the increased percentage of $4 \%, 8 \%$ and $12 \%$ of $\mathrm{MgCl}_{2}$ dry density respectively $1.85 \mathrm{gm} / \mathrm{cm}^{3}$, $1.86 \mathrm{gm} / \mathrm{cm}^{3}$ and $1.86 \mathrm{gm} / \mathrm{cm}^{3}$. The addition of salts to the soil increased the dry density and the optimum moisture content. Similar results were reported by Frydam et al [7] and Wood [8]. They attributed this behavior to the fact that at low moisture content the soil structure (before compaction) tends to change from edge-to-face type of flocculation to face-to face flocculation (salt flocculation) with the increase in salt concentration [9]. Consequently under the influence of dynamic compaction, the clay particles become more oriented and the compacted dry unit weight increases with the increase in salt content. The decrease in the optimum moisture content as the salt content increased may be explained due to the higher the face-to-face flocculation the lower is the amount of water required for lubrication.

\subsection{Atterberg Limits}

As the proportion of chloride is increased the liquid limit, plastic limit and plasticity index is decreased. This is due to the decrease in the thickness of the diffused double layer as the salt content increased. The liquid limit, plastic limit and plasticity index decreased as the salts contend increased.
Similar results were reported by Venkatabor \& Reach [10] this behavior is due to the decrease in the thickness of the diffused double layer as the salt content increased.

\subsection{Consolidation Test}

From the above figure it is observed that the swelling property is decreased, so the soil property is improved. [11]

\section{Conclusions}

(1) The maximum dry density increased and the optimum moisture content decreased with the increase in salt content.

(2) The addition of each type of the chloride compounds used in this research decreased the liquid limit, plastic limit, and the plasticity index for the soil.

(3) The compression index and swelling index was decreased with the increase in chloride compound percentage.

\section{Future Recommendation of the Study}

Base on this study, the following recommendation can be made for future research:

(1) To investigate the effect of admixture on the moisture density behavior of sandy soil.

(2) To study the geotechnical properties of stabilized soil.

(3) To investigate the influence of admixtures on stress-strain behavior.

(4) To determine better result on Unconfined Compression Strength test and Compressive stress-strain behavior test 28 days curing should be taken.

(5) To study possible settlement of the expansive soil that should be achieved before construction so that differential settlement is decrease. 
(6) To investigate the effect of more percentage of salt in soil.

(7) To investigate the effect of admixture of other chemicals or more chloride salts.

\section{References}

[1] Perloff. W. H. (1976), "Soil Mechanics, Principals and Application", New York: John Wily, \& Sons.

[2] Janathan Q. Addo, Sanders, T. G. \& Chenard, M. (2004), Road dust suppression: "Effect on unpaved Road Stabilization".

[3] Chen, F. H. (1981), "Foundation on Expansive soil", Amsterdam: Elsevier Scientific Publishing Company.

[4] White, D. (2005). Fly Ash Soil Stabilization for Non-Uniform Subgrade Soils. IHRB Project TR-461, FHWA Project 4.

[5] FM5-410, (2012). Soil Stabilization for Road and Airfield. www.itc.nl/ rossiter/Docs/FM5-410.

[6] Hicks, R. (2002). Alaska Soil Stabilization Design Guide.

[7] Frydman, I. R. \& Ehrenreich, T. (1977). Stabilization of heavy clay with potassium chloride. Journal of Geotechnical Engineering, 8, 95-107.
[8] Wood, K. B. (1971). Highway Engineering Hand Book. Chapter 21. New York: McGraw Hill Book Company, Inc.

[9] Lambe, T. W. (1958). The structure of compacted clay. Journal of Soil Mechanics and Foundation. 84, 55-70.

[10] Venkatabor Rad, G. (1977). Physico-chemical mechanism governing the plasticity behaviors of soils. Journal of Indian Geotechnical. 7, 261-282.

[11] Das, B. M. (1998), Principle of Foundation Engineering, Books/cole publishing company, CA-93950, USA.

\section{Biography}

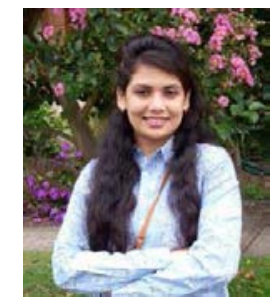

Habiba Afrin received her B. Sc. in Engineering from Department of Civil Engineering, Rajshahi University of Engineering \& Technology, Rajshahi, Bangladesh. She conducted her undergraduate thesis in the field of Soil Stabilization. Her research interest is in soil stabilization technology, environment management and Soil engineering. 